\title{
The Comparison between Health Care Providers Having Personality Type (A) Versus (B) in Using Coping Strategies in Job Burnout
}

\author{
Nora Yonis Alsomali ${ }^{1}{ }^{*}$ Ahmed Abdella Mohammed Osman ${ }^{2}$, \\ Khalid Mohammed Alzahrani ${ }^{3}$. \\ ${ }^{1}$ MSc in Puplic Administration, BSc in Hospital Administration, BSc in Radiological Science. \\ - ${ }^{2} M B B S, C S S Y B, M H P E, M D$.Faculty of Public Health \& Health Informatics, Umm Al-Qura University, KSA. \\ ${ }^{3} M B B S, M S c$, MD.Directorate of Public Health, Health Affairs, Jeddah, KSA. \\ Corresponding Author: Ahmed Abdella Mohammed Osman
}

\begin{abstract}
Job stress is considered as one of the important issues that affect people's health. We aimedto analyze the Burnout phenomenon in relation to the personality types of the $(H C P)$ and using of the coping strategies to confront this phenomenon. This is a cross sectional study in which we involved (HCPs) (doctors, specialists, and technicians) worked in Jeddah Health Affairs, Saudi Arabia. We selected the sample size from total of (13313) (HCPs). The sample size was (373) (HCPs) and we added extra 27 (HCPs) to reach (400) to guard against nonresponder; we used random cluster technique. We analyzed (391) questionnaires from total of (400) distributed questionnaires; the response rate was $(87.21 \%)$.The (HCP) having personality type (A) uses Emotional Catharsis, Surrender, Isolation, Denial, Isolation and Daydreamingstrategy more than type (B); and they have higher score of Job Burnout in regard to type (B) personality. While (HCP) having personality type $(B)$ uses positive strategies more frequently.
\end{abstract}

Keywords:Burnout; Health Care Providers; Type (A) (B) Personality.

Date of Submission: 14-07-2017

Date of acceptance: $24-07-2017$

\section{Introduction}

Job stress is considered as one of the importantissues that affect people's health [1] and more than 60 billion dollars spend annually by various organizations on work stress related diseases [2]. Healthcare serviceis one of the fundamental social services, in which medical services and nursing are playing the essentialroles in health process. In fact, health occupations possess a lot of stressful conditions; where the health staff suffers from pressures and fatigue and they develop high degrees of depression and anxiety. The stress that happens to(HCP)may interfere with their optimum duties, for example: they cannot understand the patients and some sort ofmiscommunicationwill occur. Reasons behind the stress and anxiety in doctors and nurses involve personal and impersonal factors like: life and death cases in front of their eyes, stress caused by patients and their relatives along withlong working hours extend to night and daytime [3]. Nursing as a job is described as a difficult occupation in comparison to other occupations [4].

\subsection{JOB BURNOUT}

It was defined as a "syndrome of exhaustion, cynicism and low professional efficacy" [5].Causes and sources of psychological Burnout include: occupational factors likemore stressful work environment, lack of rewards, frustration and coercion, working for prolong period of time, detachment, lack of work output control and weak job relationships. The Subjective Factors include ambitions and occupational obligation, realistic expectations, personal characteristics, lack of the ability to cope with work stress. The Social Factors: arise in the societies in which they arelacking the ability to understand the real process of diseases and recoveryso, they expect from doctors and nurse to bring the recovery of their relatives as soon as possible along with presence of bureaucratic leadership institutions. Environmental source: it involves general social conditions, economic conditions, attitudes and educational level. Organizational source: it involves lack of planning, weakness of the corporate structure, exposure to excessive work stress and lack of contribution in decision making.The stressful working environment exposes Health Care Provider (HCP) to be under internal pressure from organization and facing various conditions behind their control, and this in turn leads to decreasethe effectiveness and quality oftheir work. (HCPs) are at high risk to develop Job Burn-out, especially in intensive care setting which needs a heavy and continuous stressful and critical responsibilities; the (HCP) must respond well to unstable patients, interact with extremely severe and urgent situations and undertake accurate routines and duties [6].If (HCPs) 
developBurn-out, then their attitude towards their patients and decision making may be incorrectly or insufficiently [7].Demand-control model (DCM) tries to answer the question why high job demands lead to physical and psychological distress ('high strain' jobs) versuslow job control.Burnout prevalence in clinical professions is relatively higher than the other jobs; occupational physician (11\%), psychiatrist (9\%), general practitioners and community nurse (8\%) andsocial workers and midwifes (7\%).Symptoms of the job Burn-out: Researchers found a wide range of symptoms and signs that related to Burn-out. It may lead todigestive disorders, psychosomatic illnesses, high blood pressure, headaches and strokes, feeling of powerlessness, fatigue, teeth grinding, anxious, irritability and frustration.

Burnout stages: Burnout starts from the mildpsychological and physical changes and it can increase to reach more severe forms. Generally, it begins in conditions in which there is a high level of stress or high workload in front of higher job expectations from the employee side along with the imbalance between job resources and job demands. In the second stage there is emotional and physical exhaustion appears in form of sleep disturbances, pain fatigue and headaches. In the third stage there is a depersonalization, indifference or cynicism in form of apathy, depression and boredom. In the fourth stage there ishelplessness, despair or aversion and feelings of guilt and insufficiency.

\subsection{COPING STRATEGIES AND BURNOUT}

It is defined as "those changing cognitive and behavioral efforts developed for managing the specific external and/or internal demands judged as exceeding or surpassing the individual's own resources" [8].

Methods of coping include active-cognitive: like understandingand management of potentially stressful environment and events; active-behavioral: includes efforts that manage a stressful situation; and avoidancemethods: like refusal to face a stressful situation or problematic [9].The aim of this study is to analyze the Burnout phenomenon in relation to the personality types of the (HCP) and using of the coping strategies to confront this phenomenon.

\section{Method}

This is a cross sectional study in which we involved (HCPs) (doctors, specialists, and technicians) worked in Jeddah Health Affairs, Saudi Arabia. We selected the sample size from total of (13313) (HCPs) according to table of sample size obtained by Krejcie\& Morgan[10]. The sample size was (373) (HCPs) and we added extra 27 (HCPs) to reach (400) to guard against non-responder; we used random cluster technique. We analyzed (391) questionnaires from total of (400) distributed questionnaires; the response rate was $(87.21 \%)$.

\subsection{STUDY TOOLS}

Two scales were used in this study; the first is personality type (A and B) which based on the previous scale used by Matthews (1982). We modified measures ofinterest and soundly, impatience among individual and the sense of competition. The reliability of our scale was measured by an indexing verification method. Stability was measured using reliability coefficient $(0.89)$ and showed high consistency.The content of the scale was confirmed by group of arbitrators. Expert panel workingin medical science and educational psychology specialists were asked to check the scale and questions were buildaccording to their notes. A sample of (30) (HCPs) was chosen to check the internal consistency of the scale and it ranged between (0.44-0.68) with statistical significant at the level of (0.01). The Cronbach's (alpha) was (0.92) with high degree of internal consistency.

We divided the coping strategies into these dimensions: dealing centered appreciation, problem-based treatment and deal based on emotion along with concepts of logical analysis, confrontation and self-assurance, focus on the solution, self-adjusting, self-blame, liability, positive reinterpretation, daydream, isolation, denial, relaxation and mental separation, humor emotional catharsis, and searching for alternative activities. The face validity and internal validity of the scale were ranged from $(0.28-0.81)$ with statistical significant at the level of $(0.01)$.

\section{Results And Discussion}

Table (1) Showed the Correlation Coefficients between Dimensions of Job Burnout and Coping Strategies Used By (HCP)Having Personality Type (A):

\begin{tabular}{|l|l|l|l|l|l|}
\hline Coping Strategies & $\begin{array}{l}\text { Physical and } \\
\text { psychological } \\
\text { exhaustion }\end{array}$ & $\begin{array}{l}\text { Indifference } \\
\text { and work } \\
\text { relationship } \\
\text { disorders }\end{array}$ & $\begin{array}{l}\text { Feeling down and } \\
\text { underachievement }\end{array}$ & $\begin{array}{l}\text { Job incompatibility and } \\
\text { decrease work value. }\end{array}$ & $\begin{array}{l}\text { Burn-out } \\
\text { Logical analysis }\end{array}$ \\
\hline Focus on the solution & -0.09 & $0.10-$ & -0.09 & $-0.12^{*}$ & $-0.11^{*}$ \\
\hline Confrontation \& assertiveness & $-0.16^{* *}$ & $* * * 17-$ & $-0.20^{* *}$ & $-0.20^{* *}$ & $-0.20^{* *}$ \\
\hline Self-tuning & $-0.25^{*}$ & $* * 0.22-$ & $-0.14^{*}$ & $-0.17 * *$ & $-0.17^{* *}$ \\
\hline
\end{tabular}


The Comparison between Health Care Providers Having Personality Type (A) Versus (B) in Using

\begin{tabular}{|l|l|l|l|l|l|}
\hline Find more information & $-0.15^{* *}$ & $* 0.13-$ & $-0.12^{*}$ & $-0.15^{* *}$ & $-0.16^{* *}$ \\
\hline Take responsibility & -0.09 & $0.01-$ & 0.06 & -0.08 \\
\hline Self-blame & $0.25^{* *}$ & $* 0.14$ & $0.17^{* *}$ & $0.12^{* *}$ \\
\hline Accept a fait accompli & 0.08 & 0.000 & 0.07 & 0.01 & 0.08 \\
\hline Re-positive interpretation & $0.14^{*}$ & 0.05 & 0.09 & 0.02 & 0.04 \\
\hline Recourse to the God & $-0.20^{* *}$ & $* 0.12-$ & $-0.17^{* *}$ & $-0.18^{* *}$ \\
\hline Surrender & $0.26^{* *}$ & $* * 0.20$ & $0.23^{* *}$ & $0.20^{* *}$ & 0.09 \\
\hline Isolation & $0.28^{* *}$ & $* * 0.30$ & $0.26^{* *}$ & $0.22^{* *}$ \\
\hline Daydream & $0.31^{* *}$ & $* * 0.17$ & $0.30^{* *}$ & $0.24^{* *}$ \\
\hline Denial & $0.13^{*}$ & 0.09 & $0.20^{* *}$ & $0.14^{*}$ & $0.25^{* *}$ \\
\hline Relaxation mental separation & -0.03 & $0.06-$ & 0.02 & -0.09 \\
\hline Emotional catharsis & $0.31^{* *}$ & $* * 0.25$ & $0.27^{* *}$ & $0.27^{* *}$ & $0.20^{* * *}$ \\
\hline Humor & -0.002 & $0.04-$ & 0.05 & -0.01 & $0.15^{* *}$ \\
\hline Find Alternatives & $-0.12^{*}$ & $* 0.12-$ & -0.10 & $-0.14^{*}$ \\
\hline
\end{tabular}

* Significant at the level of $(\alpha \leq 0.05)$. ** Significant at the level of $(\alpha \leq 0.01)$.

Table1 shows that the highest value of the correlation coefficient for the coping strategies for (HCPs) havingpersonality type (A) with a total score of career burning was to use Emotional Catharsis strategy, which reached its association coefficient $(0.32)$, a statistically significant value at the significance level $(0.01)$, then Isolation Strategy (0.30) and Daydreaming Strategy (0.29) and then Self-tuning Strategy (-0.27), which had an inverse relationship by virtue of that Job Burnout leads toself-control lacking.

The higher strategies had negative values with the exception of self-tuning strategy (positive). Also, we noticed that the greater Burnout level rises among (HCP) whenever resorted to such negative strategiessuch as to escape, denial, venting, Surrender, and to be far from facing the source of Burn-out. Then the (HCP) transformed into a state of passive and enter isolation and even to withdraw from the society which in turns represents the symptoms of the Burnout phenomenon. Similar results were found [11, 12]. Also, these results showed that the (HCP) having personality type (A) are susceptible to burn more than the others.

Table (2) Showed the Correlation Coefficients between Dimensions ofJob Burnout and Coping Strategies Used By (HCP) Having Personality Type (B)

\begin{tabular}{|c|c|c|c|c|c|}
\hline Coping Strategies & $\begin{array}{l}\text { Physical and } \\
\text { psychological } \\
\text { exhaustion }\end{array}$ & $\begin{array}{l}\text { Indifference and } \\
\text { work relationship } \\
\text { disorders }\end{array}$ & $\begin{array}{l}\text { Feeling down and } \\
\text { underachievement }\end{array}$ & $\begin{array}{l}\text { Job } \\
\text { incompatibility } \\
\text { and decrease } \\
\text { work value }\end{array}$ & $\begin{array}{l}\text { Burn- } \\
\text { out }\end{array}$ \\
\hline Logical analysis & 0.24 & $* 0.36$ & 0.03 & $* 0.34$ & 0.29 \\
\hline Focus on the solution & 0.20 & 0.27 & 0.10 & 0.28 & 0.25 \\
\hline $\begin{array}{l}\text { Confrontation \& } \\
\text { assertiveness }\end{array}$ & 0.04 & 0.02 & $0.13-$ & 0.15 & 0.05 \\
\hline Self-tuning & 0.05 & 0.13 & $0.04-$ & 0.18 & 0.10 \\
\hline Find more information & $0.03-$ & 0.05 & $0.02-$ & 0.18 & 0.06 \\
\hline Take responsibility & 0.10 & 0.13 & $0.04-$ & 0.20 & 0.13 \\
\hline Self-blame & 0.16 & 0.19 & 0.08 & 0.28 & 0.21 \\
\hline Accept a fait accompli & $* 0.34$ & $* 0.39$ & 0.33 & $* 0.39$ & $* 0.39$ \\
\hline $\begin{array}{l}\text { Re-positive } \\
\text { interpretation }\end{array}$ & 0.14 & 0.21 & 0.06 & 0.25 & 0.20 \\
\hline Recourse to the God & 0.14 & 0.14 & 0.11 & 0.24 & 0.18 \\
\hline Surrender & 0.29 & $* 0.35$ & 0.30 & $* * 0.45$ & $* 0.38$ \\
\hline Isolation & $* 0.34$ & $* * 0.43$ & 0.22 & $* 0.40$ & $* 0.39$ \\
\hline Daydream & 0.32 & $* * 0.43$ & 0.33 & $* * 0.44$ & $* 0.42$ \\
\hline Denial & $0.12-$ & 0.03 & $0.01-$ & 0.12 & 0.002 \\
\hline $\begin{array}{l}\text { Relaxation mental } \\
\text { separation }\end{array}$ & 0.32 & $* 0.38$ & 0.20 & $* 0.37$ & $* 0.36$ \\
\hline Emotional catharsis & 0.31 & $* * 0.46$ & 0.31 & **0.48 & $* 0.43$ \\
\hline Humor & 0.26 & $* 0.35$ & 0.18 & 0.31 & 0.311 \\
\hline Find Alternatives & 0.11 & 0.16 & 0.05 & 0.20 & 0.15 \\
\hline
\end{tabular}

* Significant at the level of $(\alpha \leq 0.05)$. * Significant at the level of $(\alpha \leq 0.01)$. 
The strategies used to cope with Job Burnout in (HCP)havingpersonality type (B) is shown in Table (2). Results show that there is no statistically significant between strategies used to cope with job Burnout and the dimensions of the Burnout in (HCP) having personality type (B). We notes that most of these strategies were positive and this is possibly attributed to the lack of correlation between them and Job Burnout dimensions of the total score, along with the low sense of Job Burnout in (HCP)having personality type (B) perhaps due to personality traits and characteristics. Again, the results shows that the highest value of the correlation coefficient for the coping strategies for (HCP) having personality type (B) with a total score of career burning was the Emotional Catharsis Strategy reaching correlation coefficient $(0.43)$, which is significant at the level of (0.05) and also, have been associated with Job incompatibility and decrease work value (0.48) and Indifference and work relationship disorders (0.46). So, these findings perhaps explain that (HCP)having personality type (B) had lifestyle as easy and calm, patience and focus on the positive aspects of things, people and events; also, they tend to find directions to solve the problems along with their accomplishment in achieving the deadlines. They did not give all interests within the work only, but exercised their activities normally and thus understand more than anyone else in the standard sense of functional compatibility and therefore they have less sense of Burnout (relatively).As it turns out, and there is a statistically significant at the significance level (0.05) between the use of Daydreaming Strategy and Job Burnout (0.42) and was linked with Job incompatibility and decrease work value dimension (0.44) and Indifference and work relationship disorders (0.43), and these findings indicate that (HCP) havingpersonality type (B) had ease and calm lifestyle and therefore less sense of indifference and working disorders along with non-functional compatibility. Similarly it has been shown there is a correlation between the other strategies (Surrender and Isolation and Mental Relaxation and Denial) and Physical and psychological exhaustion Job Burnout dimension.In general, the low sense of (HCP) having personality type (B) with Job Burnout leads to the lack of recourse to the following strategies negative or positive (Surrender, Isolation, and Daydream and Relax and Separation of mental and Emotional Catharsis) and these results are agreed with the results of the study [13], which shows a tendency with personality type (A) to use confrontation strategies focused on the problem more than (HCP) having personality type (B) and also, it agreed with the results of [14], which showed no differences in the total score for Burnout psychological among those with the Type (B)due to using of strategies to face the problems; and agreed the results of the study with the results of [15], which found a relationship between personality type (B) and their role in clearing ambiguity and conflict.

\section{Conclusion}

Job Burnout continues to exert wide psychological problems in (HCP); there are differences in dealing with Job Burnout in (HCP) according to their personality type. The (HCP) having personality type (A) uses EmotionalCatharsis, Surrender, Isolation, Denial, Isolation and Daydreamingstrategy more than type (B); and they have higher score of Job Burnout in regard to type (B) personality. While (HCP) having personality type (B) uses positive strategies more frequently like: Self-tuning,Take responsibility,Accept a fait accompli, Re-positive interpretation, Relaxation mental separation, Emotional catharsis and Humor strategies.

\section{References}

[1] Jawahar, I M, T H. Stone, and J L. Kisamore. Role Conflict and Burnout: the Direct and Moderating Effects of Political Skill and Perceived Organizational Support on Burnout Dimensions. International Journal of Stress Management, 14(2) 2007, 142-159.

[2] Matteson, Michael T., and John M. Ivancevich. Controlling Work Stress: Effective Human Resource and Management Strategies. San Francisco, Calif. [u.a.]: Jossey-Bass, 1989.

[3] Hsiu-ChuanShen, Yawen Cheng, and Perng-Jy Tsai. Occupational Stress in Nurses in Psychiatric Institutions in Taiwan. Journal of Occupational Health. 47(3). 2005. 218-225.

[4] Vahey, D., Aiken, L., Sloane, D., Clarke, \& Vargas, D. Nurse burnout and patient satisfaction. Medical Care, 42(2), 2004. 57-66

[5] Maslach, Christina, and Susan E. Jackson. Maslach Burnout Inventory. Palo Alto, Calif: Consulting Psychologists Press, 1986.

[6] Erlen JA, and SM Sereika. Critical Care Nurses, Ethical Decision-Making and Stress. Journal of Advanced Nursing. 26(5), 1997953-61.

[7] Sawatzky. J.V. Stress in critical care nurses. Actual and perceived. Heart and Lung. 25, 1996. 409-417.

[8] Lazarus, R.S. \&Folkman, S. Estrés y procesoscognitivos. Barcelona: Editorial Martínez Roca, S.A. 1986

[9] Billings, Andrew, and Rudolf H. Moos. The role of coping responses and social resources in attenuating the stress of life events. [S.1.]: [s.n.], 1981.

[10] Krejcie, R. V., \& Morgan, D. W. Determining sample size for research activities. Emmitsburg, MD: National Emergency Training Center. 1970.

[11] Angel, B.; Anton, A. \& Joan, B. Burnout Syndrome and Coping Strategies: A structural relations Model. Psychology in Spain, 1(7), 2003. 46-55.

[12] Gmelch,W. \&Gates,G. The Impact of Personal, Professional and Organizational Characteristics on Administrator Burnout. Journal of Educational Administration, 36(1), 1998. 146-165.

[13] Ben Zeroual, F. Personality types, stress relationship and coping strategies. doctoral diss., University Mentouri Constantine, Algeria. 2008.

[14] Dardir, Karam A., Ammar. Burnout of teachers with type (A and B) and methods of confronting problems, doctoral diss., Faculty of Education, Department of Educational Psychology and Mental Health, Fayoum University, Egypt. 2007.

[15] Burke, John M. The relationship between Type A behavior, role stress, job enrichment and burnout among college counselors. doctoral diss., College of Taxes A\&M University, USA. 1985.

Nora Yonis Alsomali. "The Comparison between Health Care Providers Having Personality Type (A) Versus (B) in Using Coping Strategies in Job Burnout." IOSR Journal of Nursing and Health Science (IOSR-JNHS) 6.4 (2017): 71-74. 